\title{
Gênero, educação das mulheres e feminização do magistério no ensino básico
}

\author{
Jussara Reis Prá* \\ Amanda Carolina Cegatti*
}

\begin{abstract}
RESUMO: Neste artigo abordamos implicações da predominância de mulheres no exercício docente, traçando um panorama histórico sobre a conquista da educação feminina e seus desdobramentos no mapa da feminização do magistério no ensino básico. Com o aporte da teoria feminista crítica, advogamos que esse processo de feminização não pode ser avaliado sem levar em conta a dicotomia público/ privado na perspectiva de gênero.
\end{abstract}

Palavras Chave: Gênero. Educação. Feminização do Magistério. Feminismos.

\section{Introdução}

$\mathrm{E}$ ducação e docência estão entre os espaços sociais aos quais as mulheres acederam mais cedo e se incorporaram mais facilmente ao mundo do trabalho. Esse cenário desvelou a tendência à feminização de determinadas carreiras profissionais, áreas de estudos e certos níveis de ensino, especialmente nas etapas iniciais de instrução. Sem embargo, as demandas das mulheres por acesso à educação e ao mercado laboral exigiram delas enfrentar o desafio de reservar algum lugar às tradicionais obrigações femininas derivadas da maternidade, das funções domésticas e das tarefas de cuidado.

* Doutora em Ciência Política. Professora da Universidade Federal do Rio Grande do Sul (UFRGS) no Curso de Ciências Sociais e no Programa de Pós-Graduação em Ciência Política do Instituto de Filosofia e Ciências Humanas (IFCH). É líder do Grupo de Pesquisa Gênero, Feminismo, Cultura Política e Políticas Públicas/ CNPq. É pesquisadora produtividade CNPq. Porto Alegre/RS-Brasil. E-mail: <jussarapra@yahoo.com.br>.

** Mestranda em Ciência Política. É pesquisadora do Núcleo Interdisciplinar de Estudos sobre Mulher e Gênero coordenado pela profa. Dra. Jussara Reis Prá na UFRGS. Porto Alegre/RS - Brasil.

E-mail: <amandaccegatti@gmail.com>. 
Tal desafio, contudo, não deve ser resumido ao incremento da proporção de mulheres no corpo estudantil, docente ou profissional. Antes disso, deve ser lido desde a perspectiva de gênero, quer dizer, como fruto de modelos que configuram a forma de ser e fazer de homens e mulheres em sociedade. Em síntese, precisa ser apreciado como decorrência de um processo histórico que nutriu e ainda nutre a construção das diferenças sociais entre o masculino e o feminino (AMÂNCIO, 1994). O resultado disso é por demais conhecido e expressa, em diferentes países, situações como a infrarrepresentação das mulheres em postos decisórios ou a precarização dos salários em níveis de ensino mais feminizados.

Diante do quadro esboçado, este artigo aborda a relação mulheres e educação e suas implicações com respeito às trajetórias profissionais femininas. Nesse sentido, dirigimos a atenção às origens e às especificidades do processo de feminização do magistério. Pretendemos enfatizar esse fenômeno como resultado da construção social do trabalho docente das mulheres para examinar o caso da educação básica, com menção à realidade brasileira. Recorremos a obras clássicas da literatura feminista e da teoria política, somando-as a livros, artigos acadêmicos e a resultados de pesquisas no campo da história das mulheres e dos estudos de gênero.

A fim de desenvolver a reflexão proposta, nos filiamos à teoria feminista crítica, tendo em vista a dicotomia público/privado que fixa e naturaliza a subordinação das mulheres (OKIN, 2008). Dicotomia, a partir da qual as relações de gênero são estruturadas pelo vínculo das mulheres com a esfera doméstica (privada), situando-as em lugares subalternos na hierarquia entre os sexos e distanciando-as da esfera pública (política). Com esses aportes, estimamos colaborar com reflexões sobre os sentidos e significados da feminização do magistério. Ademais, entendemos que estudos dessa natureza podem aportar elementos para subsidiar políticas educativas e estratégias formativas que levem em conta as desigualdades de gênero na relação entre mulheres e educação.

Tendo isso em vista, seguimos a exposição, tecendo breves considerações sobre o panorama histórico relativo à luta das mulheres por cidadania. Para tanto, vamos rever algumas vozes de detratores e defensores/as dos direitos das mulheres, pautando o discurso sobre a educação feminina que se afirma desde a ilustração (Séc. XVIII). No mesmo segmento, discorremos sobre as nuances da construção de um modelo de educação diferenciado por gênero - público para os meninos e privado, doméstico, para as meninas. Para concluir o tópico, focalizamos o acesso das mulheres à esfera pública e seu direcionamento ao ensino superior e a áreas acadêmicas específicas.

Na sequência, elencamos algumas especificidades do fenômeno da feminilização (aumento quantitativo de mulheres na ocupação) e da consequente feminização da docência no ensino básico. Dessa perspectiva, abordamos diferentes formas de segregação no exercício do magistério. Tratamos brevemente da presença de docentes mulheres nos diferentes níveis de ensino (básico, médio e superior) e das desigualdades de gênero 
no plano da profissionalização, da remuneração e da participação em instâncias decisórias. Concluímos o artigo com considerações sobre a feminização do magistério, a fim de reiterar a importância da perspectiva de gênero para compreender a relação mulheres e educação.

\section{Panorama histórico da conquista de direitos à educação e à docência feminina}

Durante longos períodos da história a educação foi privilégio das classes abastadas. Desde o alunato até o corpo docente, apenas homens de famílias de "prestígio" costumavam chegar a todos os níveis de ensino. Os debates do iluminismo (séc. XVIII) fundamentaram privilégios dessa natureza no ordenamento jurídico, político e social de muitos países do continente europeu. Também no Brasil e em outras partes da América Latina, projetos políticos, inerentes à democracia moderna e às tradições liberais e republicanas, normatizaram as vantagens masculinas.

O caso francês é exemplar das negativas dos novos estados liberais à igualdade entre os sexos. Na França revolucionária vieram à tona as discussões referentes à extensão da cidadania a outros setores da sociedade, subjacentes à Declaração dos Direitos do Homem e do Cidadão (1789). Com o propósito de suprir os ideais da Revolução liberdade, igualdade e fraternidade - os franceses conquistaram, entre outros direitos, a expansão do sufrágio e da educação. Quanto às mulheres, no momento de definição dos espaços de cidadania, coube a elas um lugar subalterno nos arranjos políticos da modernidade. Nesse marco, o poder político e a liberdade civil seriam regulamentados em um contrato firmado por e entre homens. Introduzido o contrato, a dicotomia público/ privado qualifica a esfera pública, masculina (civil), em contraposição à esfera privada, feminina (natural). “O significado do que é ser um 'indivíduo', produtor de contratos e civilmente livre, é revelado através da sujeição das mulheres dentro da esfera privada" (PATEMAN, 1993, p. 28). Desafortunadamente, seria este o modelo de cidadania difundido e validado nas sociedades ocidentais.

A par disso, algumas vozes demandaram o direito das mulheres à cidadania, entre estas, a da italiana Christine de Pizan (1364-1430) e de Olympe de Gouges (1748-1793), na França, a da inglesa Mary Wollstonecraft (1759-1797) e a de Nísia Floresta (1810-1885), no Brasil. Contudo, como sabemos, reverberou nos estados modernos a voz dos detratores desses direitos, a exemplo de Rousseau (1712-1778). Nesse clima, a democracia legada pelas revoluções burguesas (americana, inglesa e francesa) projeta "a exclusão das mulheres do campo completo de bens e direitos que desenha a teoria política rousseauniana" (VALCÁRCEL, 2001, p. 8).

O cenário aludido enquadra a defesa da cidadania feminina em um contexto de crescentes reflexões, demandas e lutas feministas por igualdade entre os sexos. Manifestações 
estas fomentadas pelo pensamento ilustrado (iluminista) em momentos que circundam o das revoluções burguesas. Um breve recorrido sobre o discurso de autoras que pregaram a igualdade entre os sexos permite identificar o teor do debate em defesa da participação das mulheres na esfera pública, incluído o seu acesso à educação e a carreiras profissionais.

A Declaração dos Direitos da Mulher e da Cidadã, elaborada por Olympe de Gouges, em 1791, sintetiza o teor desses pleitos e os aportes da luta pela expansão da cidadania feminina. Visando situar as mulheres como representantes da nação, a autora redige a sua Declaração em oposição à outra, do homem. Para tal, parafraseia os dezessete artigos do documento original e inclui as mulheres em cada um deles, preconizando, com afinco, que pessoas de ambos os sexos são iguais e têm os mesmos direitos à liberdade, justiça e igualdade de oportunidades. Isso, na prática, significava reivindicar a presença feminina na esfera pública, demandando direitos como o de posse da propriedade (art.17) e de participação na vida pública e política.

Diante disso, vale destacar o Artigo 6 ${ }^{0}$ da Declaração dos Direitos da Mulher, cuja essência remete à igualdade de oportunidades na esfera pública, ressalvado o direito ao trabalho e o fim da discriminação das capacidades femininas na determinação de funções.

\footnotetext{
Artigo $6^{0}$ : A lei deve ser a expressão da vontade geral. Todas as cidadãs e cidadãos devem concorrer pessoalmente ou com seus representantes para sua formação; ela deve ser igual para todos. Todas as cidadãs e cidadãos, sendo iguais aos olhos da lei devem ser igualmente admitidos a todas as dignidades, postos e empregos públicos, segundo as suas capacidades e sem outra distinção a não ser suas virtudes e seus talentos (GOUGES, 1791).
}

Também em defesa da igualdade entre os sexos, Christine de Pizan escreve alguns séculos antes A Cidade das Damas (1405). Esta autora constrói uma cidade utópica para as mulheres e a torna "uma verdadeira fortaleza contra as injúrias presentes nos grandes clássicos da época" (CALADO, 2006, p.31). De acordo com Luciana Calado (2006, p.106), a atualidade desta obra e a sua utilidade para as mulheres repousa na projeção de futuro feita então. A prova disso, segundo ela, é o fato de que as reivindicações formuladas em A Cidade das Damas, "como o acesso da mulher ao saber, a igualdade entre os sexos, a questão da violência física contra a mulher, continuam válidas, sete séculos depois, [...] em uma decepcionante atualidade". Com efeito, tanto Pizan como Gouges tornaram visível a presença da outra metade da população que os detratores dos direitos das mulheres faziam questão de ocultar ou desqualificar.

No mesmo diapasão seguem as intervenções da feminista inglesa Mary Wollstonecraft no livro Vindicação dos Direitos da Mulher (1792). Esta autora sustenta que as mulheres não são naturalmente inferiores aos homens; mas, sim, têm menos capacidades por não desfrutarem dos mesmos privilégios de educação. Dessa maneira, sua maior bandeira será a reivindicação do direito à educação feminina em todos os níveis 
de ensino. A vindicação, na avaliação de Amelia Valcárcel (2001, p.8), “decanta a polêmica feminista ilustrada, sintetiza seus argumentos e, por sua articulação projetiva, se converte no primeiro clássico do feminismo no sentido estrito".

Não por acaso, os argumentos de Wollstonecraft se dirigiam à Rousseau para contestar os equívocos da defesa deste à obediência, submissão e ignorância como as principais diretrizes da educação feminina. No entendimento da autora, razão e autonomia constituíam elementos indispensáveis para dotar as cidadãs de práticas e conhecimento que lhes permitissem cumprir suas obrigações cívicas e domésticas. Destarte, Wollstonecraft se debatia entre duas interpretações de independência, porquanto apresentava uma versão idealizada da família matrimonial e, ao mesmo tempo, presumia um tipo de autossuficiência das mulheres que as libertava da dependência conjugal e da opressão no casamento. Assim, a autora não rompia com a dicotomia público/privado. Em contrapartida, considerava a presença das mulheres em instituições acadêmicas, profissionais, civis e políticas da esfera pública como a única forma para elas conquistarem plena autonomia. Nesse tom, fora formulado o que se convencionou chamar de o "dilema de Wollstonecraft". Um dilema que, passados dois séculos de sua formulação, seguiria presente nas demandas feministas por igualdade de direitos. E cuja máxima acompanha a trajetória profissional feminina como expressão da segregação ocupacional (vertical/ horizontal) ou dos efeitos tesoura e do teto de vidro tratados adiante.

Intervenções como as de Mary Wollstonecraft e Olympe De Gouge elucidam o conteúdo das reações do feminismo ilustrado à retórica misógina (aversão às mulheres) de seus detratores. Contudo, no decorrer do desenvolvimento do novo estado liberal e da então nascente sociedade industrial vingou a codificação sexual subjacente à Declaração dos Direitos do Homem. Tal legado, advoga Valcárcel (2001), fundamentou a exclusão das mulheres com o suporte do direito romano e das codificações napoleônicas. Derivam daí os códigos civil e penal sedimentados no mundo ocidental a partir do século XIX. Como lembra Valcárcel (2001), o código civil definia a minoridade das mulheres e sua dependência de pais, esposos ou mesmo filhos e as impedia de ter uma profissão e de exercê-la sem a autorização de um de seus "tutores"; enquanto o código penal reiterava a supremacia masculina ao fixar sanções para desvios na conduta feminina, entre eles, o adultério. Do mesmo contexto procederam outros regramentos para a exclusão das mulheres, como aqueles referentes à educação.

Nesse plano, os novos estados constitucionais oficializaram o sistema educativo. Para tanto delimitaram o ensino em três níveis (primário, médio e superior), criaram corpos funcionais e um currículo voltado ao exercício profissional, além de assumir a tarefa de avalizar os títulos acadêmicos. As mulheres, por seu turno, "ficaram excluídas formalmente dos níveis de educação médios e superiores e sua instrução primária foi considerada voluntária" (VALCÁRCEL, 2001, p.14). Ou seja, seria oferecida a meninas graças à boa vontade de alguém (ex gratia). 
Vale ressaltar desse panorama que a benevolência da qual dependiam as meninas para se instruir ficava ao encargo daquelas que se dedicavam à caridade ou filantropia. Figuras estas revestidas da imagem materna e a quem caberia transmitir ensinamentos voltados a reforçar as qualidades femininas para o cuidado do lar e da família. Delas era exigida a capacidade de reproduzir esses valores sem a necessidade de algum tipo de instrução formal. Em suma, competia a elas reafirmar o modelo da ordem social patriarcal no qual a educação da mulher ficava restrita à esfera doméstica e sob o encargo das mães.

O cenário desenhado na primeira metade do século XIX, sob o impacto das primeiras leis de Instrução Pública, demarcou a expansão da educação feminina em quase todos os países do mundo. Não obstante, o percurso para a incorporação das mulheres à rede educativa e aos diferentes níveis de ensino foi lento e problemático. Ademais, esse percurso exigiu confrontar o viés masculino e de classe do sistema educacional. Por conta disso, a educação inicial das meninas de classes mais favorecidas priorizava formar boas donas-de-casa e futuras esposas e mães, ofertando às das camadas pobres competências limitadas para atuar como mão de obra barata na unidade doméstica e fora dela.

Outro ponto a considerar é o fato do estudo das meninas diferenciar, sobremaneira, daquele oferecido aos meninos. Enquanto a educação inicial para elas era dirigida às prendas do lar, em um segundo momento o currículo escolar definia conteúdos próprios para cada sexo. Elas aprendiam a ler, depois a escrever e a contar (operações matemáticas). Logo recebiam noções de cozinha, costura e bordado, sendo esta a última etapa do aprendizado feminino, que as preparava para as tarefas do lar e a ocupação do espaço doméstico. Os meninos seguiam sua formação com aulas de geometria, história, geografia, retórica e filosofia, entre outras.

A trajetória das mulheres na docência até a sua profissionalização expressa o mesmo viés. Como esclarece Sonsoles San Román (2001, p.2) sobre a Espanha, mas aplicável a diferentes países, o lugar das mulheres no cenário da educação logo revela as desigualdades de gênero. Processo que, ressalvadas as diferenças de tempo e lugar, configura as mudanças da modernidade (políticas, sociais, econômicas, culturais e educacionais) e culmina na chegada ao segundo milênio. A partir disso, entendemos oportuno mencionar os três modelos associados pela autora ao processo de reconhecimento do magistério feminino como profissão, a saber: a professora analfabeta, a professora maternal e a professora racional intuitiva.

Seguindo Sán Roman (2001), sintetizamos os três modelos de acordo com a sua ordem de representação na trajetória de profissionalização do magistério feminino. A professora analfabeta emerge no contexto do Iluminismo. Tal figura, sem o conhecimento de escrita e leitura, era concebida como docente de escolas públicas de meninas com a tarefa de reproduzir a cultura da feminilidade, refletindo o modelo da profissional da esfera doméstica. Já a professora maternal assume pela primeira vez as escolas de meninos e, na condição de esposa, servente ou filha do professor, tem a função de 
reproduzir o ambiente familiar em sala de aula. Esse modelo desencadeia a formação feminina em escolas normais no contexto de afirmação do estado liberal. A necessidade de capacitar as mulheres para educar melhor os filhos e desenvolver melhor as tarefas domésticas induz ao modelo da professora racional intuitiva. Esta figura reafirma as diferenças sexuais, traz à tona características inerentes às mulheres (sensibilidade, emoção e instinto maternal) e dá margem para o magistério se tornar uma profissão de mulheres (SAN ROMÁN, 2001; SANCHEZ, 2009).

Na formatação do quadro da educação e do magistério feminino, as mulheres chegam ao final do século XIX conquistando o direito ao ensino superior. Ainda assim, muitas mulheres preferiram cursos e carreiras profissionais menos prestigiadas ou mais relacionadas às tarefas de cuidado e às funções domésticas - entre elas à saúde (medicina e enfermagem) e à educação (magistério). Tal concentração, conforme Alicia Palermo (2006, p.20), também pode ser lida como uma estratégia exitosa das interessadas em seguir os estudos superiores, vez que ao optarem por uma carreira considerada "mais apropriada para elas e, sobretudo, quando já havia antecedentes nessa área de estudos" enfrentariam menos barreiras para seguir um curso universitário. Nesta linha, a educação ancorou a participação feminina no mercado de trabalho ao longo do século XX, entrando no terceiro milênio e abrindo um leque de possibilidades de carreiras e profissões. Não obstante, as escolhas por determinados cursos ou carreiras ainda permanece próxima daquelas feitas no passado.

Resumindo, apesar das limitações apresentadas às mulheres no acesso ao ensino superior é correto afirmar que tal situação lhes propiciou a abertura de espaços na esfera pública. Esta conquista, por seu turno, induziu modificações de ordem estrutural, visto que nos demais níveis de educação - primário (básico) e secundário - as elites patriarcais eram capazes de garantir currículos diferenciados para meninos e meninas. Essas diferenças, que reiteravam a ideia de uma natureza divergente e desigual entre os sexos e uma suposta incapacidade intelectual das mulheres, tendiam a se diluir nos currículos do ensino superior.

Concluindo este ponto, foge ao escopo deste artigo aprofundar o debate sobre a trajetória das mulheres na educação. Ainda assim entendemos que rever pelo menos parte dessa história projeta luz sobre o presente e o futuro. Com esse pano de fundo passamos ao exame de algumas especificidades da feminização do magistério no ensino básico.

\section{A feminização do magistério no contexto da educação básica}

Quando se trata da feminização do magistério, a abordagem da dicotomia público/ privado permite compreender a configuração das relações de gênero na determinação de ambos os espaços. Como sustenta Susan Okin em Gênero, o público e o privado a sociedade 
se organiza pela manutenção dessa dicotomia. Âmbito no qual a esfera privada, que compreende o trabalho doméstico e o cuidado das crianças, é interpretada como espaço não político. Não obstante, tais tarefas são direcionadas ao sexo feminino, enquanto as funções de domínio público, político e econômico apresentam-se como atribuições estritamente masculinas. Assim,

[...] ser professora representava um prolongamento das funções domésticas e instruir e educar crianças, sob o mascaramento da missão e da vocação inerentes às mulheres, significava uma maneira aceitável de sobrevivência, na qual a conotação negativa com o trabalho remunerado feminino esvaía-se perante a nobreza do magistério (ALMEIDA, 1996, p.74).

No sentido do trecho citado, o momento da inserção da mulher na esfera pública reflete o papel reservado a ela como responsável pelo cuidado das crianças na dicotomia público/privado. Como mostra Martins (2007), o magistério integra as mulheres recorrendo a uma "vocação" feminina para o ofício e apresenta a profissão da educação básica como função adequada às atividades femininas, pois esta se relaciona à função materna de cuidado das crianças e à tarefa de educá-las e socializá-las na infância. Sán Roman (2001) adverte para o risco de usar o termo "vocação", vez que este tende a ser empregado como escudo para ocultar discursos que desvalorizam a importância da carreira e da profissão. Com efeito, isso traz à tona o "dilema de Wollstonecraft" que, como antes mencionado, leva as mulheres a um lugar apropriado segundo seu sexo. Quer dizer, o modelo "que aparecia com a professora maternal segue presente hoje como resultado do esquema de subordinação do qual não nos despojamos ainda" (SANCHEZ, 2009, p.7).

A separação por esferas pressupõe, de acordo com Margaret Maruani (1992), diferenças naturais entre os sexos no que diz respeito às habilidades e capacidades inatas de cada um, e resulta na designação de papéis naturalmente reservados a homens e mulheres na sociedade. Seria, portanto, inadequado às mulheres o exercício da vida pública. Nesse sentido, a autora considera que para a feminização acontecer deve ocorrer também a denominada "segregação horizontal", definida como a concentração de mulheres em atividades entendidas como "femininas". A fim de medir tais questões, Maruani (1992) utiliza um índice de dissimilaridade que indica o estado de concentração feminina nas diversas atividades dos países europeus. Esse índice

\section{[...] tem o valor 0 [zero] se a proporção de mulheres em cada setor for a mesma do que a proporção de mulheres no conjunto dos empregos". Por outras palavras, quanto mais o índice de dissimilaridade for elevado, mais a segregação horizontal será forte (MARUANI, 1992, p.19, grifo da autora).}

Segundo a mesma autora, a segregação horizontal, por sua vez, é acompanhada pela "segregação vertical", entendida como as dificuldades para alcançar altos postos na hierarquia profissional. Assim, mesmo com o aumento do nível de instrução e da 
presença no mercado de trabalho, as mulheres acabam sempre encontrando as mesmas dificuldades para elevar sua posição na hierarquia profissional.

Segregações dessa ordem são identificadas na literatura pelo termo "teto de vidro". Categoria esta referida às dificuldades de gênero de difícil visualização, que impedem o alcance de postos elevados na hierarquia ocupacional. Entre tais barreiras, pode-se mencionar o preconceito implícito às capacidades femininas e as responsabilidades domésticas que decaem expressivamente sobre as mulheres, ocasionando duplas e até triplas jornadas para elas (BONELLI; CUNHA; OLIVEIRA; SILVEIRA, 2008).

Tal segregação é situada por Márcia Barbosa (2005) em dados, indicando que atualmente as mulheres conseguem se inserir em carreiras profissionais, mas ao longo destas, são cortadas. Este fenômeno é denominado pela autora como Efeito Tesoura, e refere-se à queda na proporção de mulheres nos níveis mais elevados da carreira. Na mesma direção, Maria da Glória Bonelli et al. (2008) mostram que a trajetória profissional das mulheres em profissões tradicionalmente entendidas como femininas geralmente é interrompida devido à gravidez e/ou a dedicação temporária à vida familiar (doméstica). Homens presentes nestas mesmas profissões, isentos de tais encargos, detêm condições para dedicar-se exclusivamente à carreira e à especialização. Tais condições valorizam seu currículo profissional, o que se reflete tanto no prestígio, quanto no salário.

As noções de teto-de-vidro e de efeito tesoura podem ser visualizadas no magistério feminino em estatísticas relacionadas à presença de mulheres nos diferentes níveis da docência. De acordo com Senkevics (2011), dados referentes ao ano de 2007 indicavam que entre os profissionais da docência na creche $97,9 \%$ eram mulheres, índice reduzido a $74,4 \%$ no ensino fundamental e a $64,4 \%$ no ensino médio, enquanto no ensino superior $45 \%$ do corpo docente eram compostos por mulheres. Dados que tendem a se manter constantes. Algumas pesquisas também detectaram que as professoras universitárias se encontravam neste momento frequentemente concentradas nas especialidades ditas femininas (educação, humanidades, biblioteconomia e enfermagem). Outros indicadores são utilizados para avaliar a situação das mulheres na vida acadêmica: titulação (graduação, mestrado e doutorado) e função (auxiliares de ensino, assistentes, associados e titulares), demonstrando a mesma configuração piramidal observada nos diferentes graus de ensino, que situa o segmento feminino nos postos mais baixos da hierarquia educacional.

Como resultado dessas segregações, o fenômeno da feminização no magistério caracteriza-se pela desqualificação do ofício docente no ensino básico. Situação refletida, especialmente, nas diferenças salariais. O Jornal BBC apresenta este quadro ao situar o nível salarial das mulheres no Brasil. Segundo Bandeira (2015), elas trabalham de graça desde o dia 19 de outubro até o final de cada ano. O cálculo feito com base em estatísticas do IBGE mostra que a diferença média entre os salários de homens e mulheres no Brasil, para quem trabalha 40 horas por semana, é de 20,32\%. Isso, na prática, significa 
que, mesmo trabalhando 365 dias do ano, as mulheres recebem apenas pelo trabalho de 291 dias (BANDEIRA, 2015).

Problemas atinentes à discriminação segregam mulheres na esfera do trabalho e tendem a gerar desigualdades salariais, além de dificultar a obtenção de empregos e a ocupação de cargos decisórios na hierarquia profissional. Destarte, a tendência à presença de mulheres nas diversas etapas de ensino é inversamente proporcional à valorização de cada nível de ensino; os professores do ensino superior, majoritariamente homens, mestres e doutores, recebem maiores salários e detêm maior prestígio social, enquanto as professoras do ensino básico, na sua maioria mulheres, com menos formação, recebem salários menores e pouco reconhecimento pela profissão.

Abreviando, podemos dizer que muitas mudanças foram operadas a favor das mulheres, sem esquecer que desde muito cedo as feministas vêm lutando ponto a ponto para tal. Mas também não se pode desconhecer a permanência de obstáculos a impedir avanços reais e permanentes. Parafraseando Inma Sanchez $(2009$, p. 7) é pertinente afirmar que "a educação não pode ser uma fonte a mais de desigualdade, senão o instrumento que nos leve, de verdade, ao conhecimento e à mudança que se buscava na lustração".

\section{Considerações Finais}

Como vimos no decorrer da exposição, a feminização do magistério no ensino básico não é um fenômeno novo. Tal fato carrega uma carga histórica, situando no momento das revoluções burguesas a intensificação das denúncias feministas em relação a desigualdades de oportunidades entre os sexos. Tais denúncias expressaram reivindicações em favor da extensão da cidadania feminina, incluindo o direito à educação e à participação das mulheres na esfera pública. Essas reivindicações exerceram um importante papel na conquista das mulheres à sua presença nos espaços públicos no mundo todo.

Entretanto, este êxito também exacerbou a dicotomia público/privado. Nessa estrutura, as funções femininas, permaneciam limitadas à esfera doméstica, enquanto competia aos homens o exercício da vida pública. Assim, entendeu-se por muito tempo a separação das duas esferas como naturalmente pressuposta, devido às diferenças sexuais naturais entre homens e mulheres. Essas dissimilaridades designavam as capacidades e, por consequência, as funções inatas de cada sexo.

A entrada das mulheres no espaço público foi feita, primeiramente, através da sua inserção na educação básica, onde o ensino era utilizado para reforçar os aprendizados necessários às atribuições domésticas, limitando o seu conhecimento em outras áreas. Posteriormente, sua inserção no ensino superior e entrada no mercado de trabalho foram influenciadas por suas obrigações domésticas. Esta situação levou as mulheres a 
se concentrar em áreas voltadas ao cuidado, como a enfermagem e a educação - fenômeno denominado feminilização -, o que acabou por alterar o seu significado e o valor social, desenvolvendo o fenômeno da feminização de algumas ocupações.

A teoria feminista crítica reitera a ideia defendida no passado de que não há razão biológica ou "natural" que determine a persistência de diferenças sociais, econômicas e de poder entre homens e mulheres. Características subjetivas e papéis atribuídos a cada um resultam de um complexo ordenamento social e de expressões particulares, de acordo com épocas, culturas e a capacidade de incidência de determinados grupos sociais. Por isso, as análises de gênero levam em conta o fato de nenhuma sociedade designar às características atribuídas às mulheres (ou ao feminino) valor igual às associadas aos homens (ou ao masculino); em consequência, as diferenças entre ambos se expressam na ordem hierárquica de predomínio masculino (PRÁ, 2005).

Esta hierarquia pode ser observada nos efeitos da feminização das profissões. Ofícios como o de professora da educação básica, onde mulheres estão em maioria, são desqualificados frente à ocupação de professores do ensino superior. Tal desqualificação é vista especialmente nas diferenças salariais, onde fica demonstrada a face mais visível das desigualdades profissionais, o que leva à identificação das disparidades salariais barreiras quase intransponíveis como a do teto-de-vidro ou do efeito tesoura.

Por fim, nota-se que, apesar das mudanças em relação à presença feminina no espaço público, ainda hoje se encontram enormes disparidades em relação à igualdade de oportunidade entre homens e mulheres. Mesmo em ocupações onde as mulheres são maioria, estas aparecem em postos vulneráveis, enquanto os homens estão posicionados no topo da hierarquia profissional. Além disso, é possível ter em vista que as atribuições femininas, apesar de terem se estendido à esfera pública, não deixaram para trás o trabalho doméstico não remunerado. Concluindo estas linhas, queremos reiterar a importância de ampliar o investimento feminista e da perspectiva de gênero para compreender melhor o fenômeno feminização do magistério e a relação mulheres e educação.

Recebido em maio de 2016 e aprovado em junho de 2016

\section{Referências}

AMÂNCIO, Lígia. Masculino e feminino. A construção social da diferença. Lisboa: Afrontamento, 1994.

ALMEIDA, Jane Soares de. Mulheres na escola: Algumas reflexões sobre o magistério feminino. Cadernos de Pesquisa, São Paulo, n.96, 71-78, fev., 1996. 
BANDEIRA, Luiza. Desigualdade: mulheres brasileiras trabalham 'de graça' desde 19 de outubro. BBC Brasil, Londres: 2015. Disponível em: <http://www.bbc.com/portuguese/noticias/2015/11/151110_ mulheres_trabalho_gratis_lab>. Acesso em: mar. 2016.

BONELLI, Maria da Gloria; CUNHA, Luciana; OLIVEIRA, Fabiana de; SILVEIRA, Maria Natália da. Profissionalização por gênero em escritórios paulistas de advocacia. Revista Tempo Social, São Paulo, v.20, n.1, 265-290, 2008.

CALADO, Luciana Eleonora de Freitas. A cidade das damas: a construção da memória feminina no imaginário utópico de Chistine de Pizan. 2006. 371 f. Tese (Doutorado em Letras) - Programa de PósGraduação em Letras, Universidade Federal de Pernambuco, Recife, 2006.

GOUGES, Olympe de. Declaração dos Direitos da Mulher e da Cidadã. Comissão de Direitos Humanos da USP. São Paulo. Disponível em: <http://www.direitoshumanos.usp.br/index.php/ Documentos-anteriores-à-criação-da-Sociedade-das-Nações-até-1919/declaracao-dos-direitos-damulher-e-da-cidada-1791.html>. Acesso em: mar. 2016.

MARUANI, Margaret. As mulheres no mercado de trabalho: tendências e evoluções nos doze países da Comunidade Europeia. Cadernos de Mulheres da Europa. Comissão das Comunidades Europeias, n.36, mar., 1992.

OKIN, Susan Moller. Gênero, o público e o privado. Estudos Feministas, Florianópolis, UFSC, v.16, n.2, 305-332, maio-ago., 2008.

PALERMO, Alicia Itatí. El acceso de las mujeres a la educación universitaria. Revista Argentina de Sociología, v. 4, n. 7, 11-46, nov.-dez., 2006.

PATEMAN, Carole. O Contrato Sexual. São Paulo: Paz e Terra, 1993.

PIZAN, Christine de. La Cité des Dames (1405). Versão Portuguesa: A Cidade das Mulheres. Lisboa: Coisas de ler Edições, 2007.

PRÁ, Jussara Reis. A mulher e o acesso à educação a partir do século XVIII. Ciências e Letras, Porto Alegre,n. 25, 227-243, Edição Especial, 1999.

. O custo político das desigualdades de gênero e a teoria do capital social. Educação Unisinos,

São Leopoldo, v.9, n.2, 99-115, maio-ago, 2005.

RABELO, Amanda Oliveira. A mulher e docência: historicizando a feminização do magistério. Revista do Mestrado de História, Vassouras, v.9, n.9, 41-53, 2007.

ROUSSEAU, Jean-Jacques. O Contrato Social. São Paulo: Editora L\&PM, 2014.

SAN ROMÁN, Sonsoles. Género y construcción de identidad profesional: el caso de la maestra en vías de profesionalización. Education Policy Analysis Archives, v.9, n.19, 11-24, maio, 2001,

. La feminización de la profesión: identidad de género. RASE, v. 3, n. 3, 376-387, 2010. Disponível em: <http:/www.ase.es/rase>. Acesso em: abr. 2016

SÁNCHEZ, Inma Mora. De madres a hijas, del hogar a la escuela: La feminización del magisterio desde la Ilustración a nuestros días, 2009. Disponível em: < https://inmamsanchez.files.wordpress. com/2010/05/de_madres_a_hijas_feminizacion_magisterio.pdf $>$. Acesso em: abr.2016.

SENKEVICS, Adriano. A Feminização do Magistério. Ensaios de Gênero. 2011. Disponível em: <http:// ensaiosdegenero.wordpress.com/2011/12/05/a-feminizacao-do-magisterio>. Acesso em: mar. 2016. 
VARCÁRCEL, Amelia. La memoria colectiva y los retos del feminismo. CEPAL-ECLAC/Naciones Unidas: Unidad Mujer y Desarrollo, Santiago de Chile, 2001.

YANNOULAS, S. C. Notas para a integração do enfoque de gênero na educação profissional. In: VOGEL, Arno (Org.). Trabalhando com a diversidade no PLANFOR, São Paulo: UNESP, 69-105, 2001.

Feminização ou Feminilização? Apontamentos em torno de uma categoria. Temporalis, Brasília, n.22, 271-292, jul.-dez., 2011.

WOLLSTONECRAFT, Mary. A Vindication of the Rights of Woman (1792). Versão Brasileira: Reivindicação dos Direitos da Mulher. São Paulo: Editora Boitempo, 2016. 


\title{
Gender, education of women and the feminization of teaching in basic education
}

\begin{abstract}
In this article we discuss the implications of the predominance of women in the teaching profession, by outlining a historical overview of the achievement of female education and its consequences in general on the feminization of teaching in primary education. With the contribution of feminist critical theory, we advocate that this process of feminization cannot be assessed without taking into account the public / private dichotomy from a gender perspective.
\end{abstract}

Keywords: Gender. Education. Feminization of the magisterium. Feminisms.

\section{Genre, éducation des femmes et féminisation de l'enseignement au niveau basique}

RÉSUMÉ: Dans cet article nous traitons des implications de la prédominance des femmes dans la pratique enseignante, en ébauchant, sur la carte de la féminisation de l'enseignement basique, un panorama historique de la conqueete de l'éducation féminine et de ses conséquences. A partir de la contribution de la théorie féministe critique, nous plaidons que ce processus de féminisation se peut être évalué sans la prise en compte de la dichotomie public/privé dans la perspective du genre.

Mots-clés: Gente. Education. Féminisation de l'enseignement. féminismes.

\section{Género, educación de las mujeres y feminización del magisterio en la enseñanza básica}

RESUMEN: En este artículo abordamos las implicaciones de la preponderancia de mujeres en el ejercicio docente y trazamos un panorama histórico de la conquista de la educación femenina y sus materializaciones en el mapa de la feminización del magisterio en la enseñanza básica. Con la aportación de la teoría feminista crítica, defendemos que no se puede evaluar ese proceso de feminización sin considerar la dicotomía público/privado en la perspectiva de género.

Palabras clave: Género. Educación. Feminización del Magisterio. Feminismos. 